\title{
Comparison of azithromycin and erythromycin in the treatment of mycoplasma pneumonia in children
}

\author{
Rui Han ${ }^{1}$, Qianqian Yu², Guohui Zhang ${ }^{3}$, \\ Baoqiang $\mathrm{Li}^{4}$, Shuzhen $\mathrm{Han}^{5}$, Guiying $\mathrm{Li}^{6}$
}

\begin{abstract}
Objective: To study and compare the clinical effects of azithromycin and erythromycin on children with mycoplasma pneumonia.

Methods: Total 132 children with mycoplasma pneumonia who were admitted to our hospital between November 2017 and September 2018 were selected as the research subjects. All the children were divided into an observation group and a control group according to random number table, 66 each. The observation group was treated with azithromycin, while the control group was treated with erythromycin. The therapeutic effect, incidence of adverse reactions and disappearance time of clinical symptoms were compared between the two groups.

Results: The total efficacy of the observation group was $98.04 \%$, and that of the control group was $74.51 \%$; there was a significant difference $\left(X^{2}=7.184, P=0.007\right)$. The incidence of adverse reactions in the observation group was $15.69 \%$, significantly lower than that in the control group $(41.18 \%)\left(X^{2}=6.376, P=0.002\right)$. The disappearance of fever, cough, rale and $X$ ray shadow of the observation group was significantly earlier than that of the control group, and the difference was statistically significant $(P<0.05)$.

Conclusion: Compared with erythromycin, azithromycin is more effective in the treatment of mycoplasma pneumonia in children. Azithromycin can further shorten the improvement time of clinical symptoms and signs and has few adverse reactions and high safety. It is worth clinical application.
\end{abstract}

KEYWORDS: Azithromycin, Erythromycin, Children, Clinical efficacy, Mycoplasma pneumonia.

doi: https://doi.org/10.12669/pjms.36.2.1441

How to cite this:

Han $R$, Yu Q Zhang G, Li B, Han S, Li G. Comparison of azithromycin and erythromycin in the treatment of mycoplasma pneumonia in children. Pak J Med Sci. 2020;36(2):156-159. doi: https://doi.org/10.12669/pjms.36.2.1441

This is an Open Access article distributed under the terms of the Creative Commons Attribution License (http://creativecommons.org/licenses/by/3.0), which permits unrestricted use, distribution, and reproduction in any medium, provided the original work is properly cited.

1. Rui Han,

Department of Pediatrics (I),

2. Qianqian Yu,

Department of Respiration,

3. Guohui Zhang,

Department of Pediatrics (II),

4. Baoqiang $\mathrm{Li}$,

Department of Pediatrics (II),

5. Shuzhen Han,

Neonatal Intensive Care Unit (NICU),

6. Guiying $\mathrm{Li}$,

Department of Pediatrics (I),

1-6: Binzhou People's Hospital, Shandong, 256610, China.

Correspondence:

Rui Han

Department of Pediatrics (I) Binzhou People's Hospital,

No. 515 Huanghe $7^{\text {th }}$ Road, Shandong, 256600, China.

E-mail: hanruiruihanrui@163.com

* Received for Publication:

July 30, 2019

* Revision Received:

* Revision Accepted:
October 26, 2019

October 27, 2019

\section{INTRODUCTION}

Mycoplasma pneumonia is a common respiratory disease caused by mycoplasma pneumoniae. ${ }^{1,2}$ It is reported that the main clinical manifestations of mycoplasma pneumonia include fever, expectoration, anorexia, headache, sore throat, etc. However, it has been found that the clinical symptoms of mycoplasma pneumonia in patients are related to the age of patients, and the smaller the age, the more atypical the clinical symptoms of mycoplasma pneumonia.,

At present, the pathogenesis of mycoplasma pneumonia in children has not been clearly defined clinically, but it is considered being related to autoimmunity and humoral immunity of children. ${ }^{5,6}$ Therefore, the clinical treatment of mycoplasma pneumonia in children is mainly 
drug therapy. At present, the most commonly used drugs are macrolide antibiotics. Azithromycin and erythromycin are macrolide antibiotics, which have good inhibitory effect on mycoplasma. ${ }^{7,8}$ This study compared the clinical efficacy of azithromycin and erythromycin through treating children with mycoplasma pneumonia, with the intention of providing a reference for clinics.

\section{METHODS}

One hundred and thirty-two children with mycoplasma pneumonia who were admitted to our hospital between November 2017 and September 2018 were selected as the study subjects. The calculation of the sample size followed the following formula:

$$
\mathrm{n}=2 *[(\alpha \beta) \sigma / \delta] \wedge 2,
$$

where $\delta$ represent the required distinction degree, $\sigma$ represents the overall standard deviation or its estimated value s, and $\alpha$ and $\beta$ can be checked out from the row of degree of freedom $v=\infty-$ in the table of $t$ critical value.

The diagnostic criteria followed was of mycoplasma pneumonia in children in Practical Paidonosology. The inclusive criteria were conforming to the diagnostic criteria of mycoplasma pneumonia in children, receiving no treatment of hormone and antibiotics, and having no other extrapulmonary complication. They were divided into a control group and an observation group according to random number table method, 66 each. The control group consisted of 21 males and 45 females, aged from one to 15 years, with an average age of $(7.9 \pm 2.4)$ years; the duration of mycoplasma pneumonia was 2 to 11 days (average (7.16 \pm 1.14$)$ days. There were 31 males and 35 females in the observation group, aged from two to 14 years, with an average age of $(8.3 \pm 2.6)$ years; the duration of mycoplasma pneumonia was 3 to 12 days (average ( $7.85 \pm 1.94)$ days). There was no significant difference in the general data such as sex and age between the two groups ( $P>0.05)$; therefore, the results of the two groups could be compared. This study was approved by the ethics committee (Ref. No. 134, dated May 8, 2019) of our hospital. All the family members of the selected children signed informed consent Form.

Therapeutic methods: All the children were given the same conventional treatment, including cough relief, phlegm resolving, heat clearing, etc. The control group was treated with erythromycin (Beijing Shuanghe Pharmaceutical Co., Ltd.,
China; State Food and Drug Administration approval number: H11021588) on the basis of the conventional treatment. Firstly, the patients were treated by intravenous injection of $20 \mathrm{mg} /$ $\mathrm{kg}$ erythromycin and $200 \mathrm{~mL}$ of glucose solution, once a day. After the disease condition became stable, the patients were given oral administration of $100 \mathrm{mg} / \mathrm{kg}$ erythromycin for suspension (State Food and Drug Administration approval number: H10970222), twice a day, for two weeks. The observation group was treated with azithromycin in addition to the conventional treatment. Firstly, they were treated by intravenous injection of $100 \mathrm{mg} / \mathrm{kg}$ azithromycin (State Food and Drug Administration approval number: H20064098) and $200 \mathrm{~mL}$ of glucose solution, once each day. After the disease condition became stable, the patients were given oral administration of $5 \mathrm{mg} / \mathrm{kg}$ azithromycin granules, twice a day, for two weeks.

Observation indicators: (1) The clinical efficacy of the two groups was observed. The evaluation criteria of curative effect were as follows. ${ }^{9}$ Efficacy was considered as significant if all the clinical symptoms completely disappeared, the vital signs completely disappeared, and the X-ray chest film examination indicated no symptoms of pneumonia. Treatment was considered as effective if the clinical symptoms relieved significantly, the vital signs significantly relieved, and the X-ray chest film examination indicated mild symptoms of pneumonia. Treatment was evaluated as ineffective if the clinical symptoms remained unchanged or even aggravated. Total effective rate $=$ (number of significantly effective cases + number of effective cases)/total number of cases $\times 100 \%$.

(2) The disappearance time of clinical symptoms of the two groups after treatment was observed.

(3) The occurrence of adverse reactions in the two groups was observed and recorded.

Statistical analysis: SPSS20.0 was used to analyze and process the data. Measurement data was expressed as Mean \pm Standard Deviation and processed by $\mathrm{t}$ test. Counting data was expressed by $\%$ and processed by $X^{2}$ test. Difference was considered statistically significant if $\mathrm{P}<0.05$.

\section{RESULTS}

The total effective rate of the observation group was $95.5 \%$, significantly higher than that of the control group $(81.8 \%)(\mathrm{P}<0.05$, Table-I).

The time of fever abatement, cough disappearance, rale disappearance and X-ray shadow disappearance in the observation group 
Table-I: Clinical efficacy between the two groups (\%).

\begin{tabular}{lcccc}
\hline Group & $\begin{array}{c}\text { Observation } \\
\text { group }\end{array}$ & $\begin{array}{c}\text { Control } \\
\text { group }\end{array}$ & $X^{2}$ & $P$ \\
\hline Markedly effective & $38(57.6)$ & $26(39.4)$ & $/$ & $/$ \\
Effective & $25(37.9)$ & $28(42.4)$ & & \\
Ineffective & $3(4.5)$ & $12(18.2)$ & & \\
Total effective rate & $63(95.5)$ & $54(81.8)$ & 7.184 & 0.007 \\
\hline
\end{tabular}

was significantly shorter than that in the control group, and the difference was statistically significant $(\mathrm{P}<0.05$, Table-II).

The incidence of adverse reactions in the observation group was $10.6 \%$, significantly lower than that in the control group $(25.0 \%) \quad(\mathrm{P}<0.05$, Table-III).

\section{DISCUSSION}

Mycoplasma pneumoniae infection is the main pathogenic factor of mycoplasma pneumonia in children. A study showed that about $9.6 \% \sim 66.7 \%$ of lung infections were caused by mycoplasma pneumoniae. ${ }^{10}$ Mycoplasma pneumonia in children is a common respiratory tract disease, and its incidence shows an increasing tendency in recent years. ${ }^{11,12}$

Considering that children with mycoplasma pneumonia are in the stage of physical development, appropriate antibiotics should be selected in the course of treatment. Macrolide antibiotics are the primary drugs for the treatment of mycoplasma pneumoniae infection. Erythromycin is a common drug for the treatment of mycoplasma pneumonia and is also the most commonly used drug in grassroots hospitals. ${ }^{13}$ Erythromycin can effectively alleviate the clinical symptoms of children, reduce lung shadow and shorten the course of disease. However, a study points out that erythromycin is unstable in acidic environment and easy to have problems such as decomposition, which will lead to gastrointestinal adverse reactions. ${ }^{14}$ Moreover, erythromycin generally has large dose, slow infusion and long course. The long-term intravenous injection can easily cause pain on the puncture site and phlebitis, and many children cannot adhere to the treatment, resulting in poor compliance.
Table-III: Occurrence of adverse reactions between the two groups during treatment (\%).

\begin{tabular}{lcccc}
\hline Group & $\begin{array}{c}\text { Observation } \\
\text { group }\end{array}$ & $\begin{array}{c}\text { Control } \\
\text { group }\end{array}$ & $X^{2}$ & $P$ \\
\hline Local pain & $2(3)$ & $7(10.6)$ & $/$ & $/$ \\
Rash & $1(1.5)$ & $4(6.1)$ & & \\
Gastrointestinal reaction & $4(6.1)$ & $5(7.6)$ & & \\
Liver function damage & $0(0)$ & $1(1.5)$ & & \\
Incidence of & $7(10.6)$ & $17(25.8)$ & 6.376 & 0.002 \\
adverse reactions & & & & \\
\hline
\end{tabular}

Azithromycin is a new macrolide antibiotic, which can block the synthesis of proteins by fully combining the ribosome subunits of pathogens to achieve the purpose of antimicrobial activity. In the treatment of mycoplasma pneumonia in children, azithromycin has the following advantages: ${ }^{15-17} 1$ ) it has a broad spectrum of antimicrobial agents, i.e., it can inhibit and kill most Gram-negative and positive bacteria; 2 ) it has good tissue permeability, i.e., it can quickly reach the infected site and enhance the drug concentration of the infected site; 3 ) it has a long half-life of plasma drug, i.e., more than 40 days; the stability of azithromycin is 300 times higher than that of erythromycin, which can reduce the number of medications and improve the compliance of children.

Clinical effects of azithromycin and erythromycin on children with mycoplasma pneumonia were compared and analyzed in this study. The results showed that the total effective rate of the observation group was $95.5 \%$, which was significantly higher than that of the control group (81.8\%), The result was similar to the results of Yang. ${ }^{18}$ In addition, in the study of Tang, ${ }^{19} 90$ children with mycoplasma pneumonia were selected and randomly divided into a control group and a research group. They were treated with intravenous infusion of erythromycin and sequential therapy of azithromycin respectively. The results showed that the disappearance time of cough and rale in the research group was significantly shorter than that in the control group, which was also confirmed by the results of this study. In this study, the results showed that the disappearance time of fever, cough,

Table-II: Disappearance time of symptoms and signs between the two groups [(Mean $\pm S D), d]$.

\begin{tabular}{lcccc}
\hline Group & Observation group & Control group & $t$ & $P$ \\
\hline Antipyretic time & $2.88 \pm 1.25$ & $5.72 \pm 1.54$ & 9.218 & 0.001 \\
Cough disappearance time & $9.02 \pm 1.97$ & $12.33 \pm 3.72$ & 5.634 & 0.014 \\
Disappearance time of rale & $7.25 \pm 2.46$ & $11.13 \pm 3.48$ & 6.517 & 0.005 \\
Disappearance time of X-ray shadow & $3.22 \pm 1.01$ & $6.98 \pm 1.56$ & 13.372 & 0.000 \\
\hline
\end{tabular}


rale and X-ray shadow of the observation group was significantly shorter than that of the control group, suggesting that the clinical effect of azithromycin was more significant. Moreover, the incidence of adverse reactions in the observation group was significantly lower than that in the control group, which indicated that azithromycin was safe, similar to the previous research results. ${ }^{20,21}$ The reason was that the chemical structure of azithromycin was more stable and its half-life was long, which was helpful to reduce the symptoms appeared in the treatment process.

\section{CONCLUSION}

In conclusion, azithromycin is more effective than erythromycin in the treatment of mycoplasma pneumonia in children. It can significantly shorten the disappearance time of clinical symptoms and has less adverse reactions and high safety. It is worth further clinical application.

Declaration of interest: All authors declared there was no conflict interests involved.

\section{Grant Support \& Financial Disclosures: None.}

\section{REFERENCES}

1. Lee KY, Lee HS, Hong JH, Lee MH, Lee JS, Burgner D, et al. Role of prednisolone treatment in severe Mycoplasma pneumoniae pneumonia in children. Pediatr Pulmonol. 2010;41(3):263-268. doi: $10.1002 /$ ppul.20374

2. Youn YS, Lee KY. Mycoplasma pneumoniae pneumonia in children. Korean J Pediatr. 2012;55(2):42-47. doi: 10.3345/ kjp.2012.55.2.42

3. Kawai Y, Miyashita N, Kubo M, Akaike H, Kato A, Nishizawa $\mathrm{Y}$, et al. Therapeutic efficacy of macrolides, minocycline, and tosufloxacin against macrolide-resistant Mycoplasma pneumoniae pneumonia in pediatric patients. Antimicrob Agents Chemother. 2013;57(5):2252-2258. doi: 10.1128/ AAC.00048-13

4. Izumikawa K, Izumikawa K, Takazono T, Kosai K, Morinaga Y, Nakamura S, et al. Clinical features, risk factors and treatment of fulminant Mycoplasma pneumoniae pneumonia: A review of the Japanese literature. J Infect Chemother. 2014;20(3):181-185. doi: 10.1016/j.jiac.2013.09.009

5. Youn YS, Lee KY, Hwang JY, Rhim JW, Kang JH, Lee JS, et al. Difference of clinical features in childhood Mycoplasma pneumoniae pneumonia. BMC Pediatr. 2010;10(1):48. doi: 10.1186/1471-2431-10-48

6. Xu YC, Zhu LJ, Xu D, Tao XF, Li SX, Tang LF, et al. Epidemiological characteristics and meteorological factors of childhood Mycoplasma pneumoniae pneumonia in Hangzhou. World J Pediatr. 2011;7(3):240-244. doi: 10.1007/ s12519-011-0318-0

7. Lee PI, Wu MH, Huang LM, Chen JM, Lee CY. An open, randomized, comparative study of clarithromycin and erythromycin in the treatment of children with communityacquired pneumonia. J Microbiol Immunol. 2008;41(1):54-61.

8. Williams DJ, Shah SS. Community-acquired pneumonia in the conjugate vaccine era. J Pediat Inf Dis Soc. 2012;1(4):314-328. doi: $10.1093 /$ jpids/pis101
9. You SY, Jwa HJ, Yang EA, Kil HR, Lee JH. Effects of methylprednisolone pulse therapy on refractory mycoplasma pneumoniae pneumonia in children. Allergy Asthma Immun. 2014;6(1):22-26. doi: 10.4168/aair.2014.6.1.22

10. Youn YS, Lee SC, Rhim JW, Shin MS, Kang JH, Lee KY. Early additional immune-modulators for mycoplasma pneumoniae pneumonia in children: An observation study. Infect Chemother. 2014;46(4):239-247. doi: 10.3947/ic.2014.46.4.239

11. Inamura N, Miyashita N, Hasegawa S, Kato A, Fukuda Y, Saitoh A, et al. Management of refractory Mycoplasma pneumoniae pneumonia: utility of measuring serum lactate dehydrogenase level. J Infect Chemother. 2014;20(4):270-273. doi: 10.1016/j.jiac.2014.01.001

12. Cheng $\mathrm{H}$, Liu L, Qiao HM, Lu JR, Yin JN, Cheng HJ. Epidemiology and clinical manifestations of children with macrolide-resistant Mycoplasma pneumoniae pneumonia in China. Paediatr Respir Rev. 2013;14(Suppl2):S64-S64. doi: 101.1016/S1526-0542(13)70087-3

13. Bebear C, Pereyre S, Peuchant O. Mycoplasma pneumoniae: susceptibility and resistance to antibiotics. Future Microbiol. 2011;6(4):423-431. doi: 10.2217/fmb.11.18

14. Li SL, Sun HM, Zhao HQ, Cao L, Yuan Y, Feng YL, et al. A single tube modified allele-specific-PCR for rapid detection of erythromycin-resistant Mycoplasma pneumoniae in Beijing. Chin Med J. 2012;125(15):2671-2676. doi: 10.3760/cma.j.is sn.0366-6999.2012.15.005

15. Dokic D, Poposki B, Karkinski D. Azithromycin in treatment of patients with asthma and C. Pneumoniae infection. Pril (Makedon Akad Nauk Umet Odd Med Nauki). 2013;34(2):71-77.

16. Xiao Z, Jiang Y, Gao X, Lin S, Lin Y, Liu X, et al. Comparison of the ameliorative effects of Qingfei Tongluo formula and azithromycin on Mycoplasma pneumoniae pneumonia. J Nat Med. 2017;71(4):685-692. doi: 10.1007/s11418-017-1098-1

17. Kawai Y, Miyashita N, Kubo M, Akaike H, Kato A, Nishizawa $Y$, et al. Therapeutic efficacy of macrolides, minocycline, and tosufloxacin against macrolide-resistant Mycoplasma pneumoniae pneumonia in pediatric patients. Antimicrob Agents Chemother. 2013;57(5):2252-2258. doi: 10.1128/AAC.00048-13

18. Yang D, Chen L, Chen Z. The timing of azithromycin treatment is not associated with the clinical prognosis of childhood Mycoplasma pneumoniae pneumonia in high macrolideresistant prevalence settings. Plos One. 2018;13(1):e0191951. doi: 10.1371/journal.pone.0191951

19. Tang XR. Clinical analysis of sequential azithromycin and erythromycin intravenous drip in the treatment of mycoplasma pneumonia in children. Guide Chin Med. 2013;(9):230-231. doi: 10.3969/j.issn.1671-8194.2013.09.182

20. Fang $X$, Wang $Q$, Jin $Y$. Clinical efficacy of azithromycin and erythromycin in the treatment of mycoplasma pneumonia in children. Mod Diagn Treat. 2015;26(19):4414-4415.

21. Peng JB, Chen BB, Deng CH. Efficacy of azithromycin and erythromycin in treatment of mycoplasma pneumonia and effects on immunoglobulins and tymphocyte subsets. Med Innov China. 2015;12(14):54-57. doi: 10.3969/j.issn.16744985.2015.14.018

\section{Authors' Contribution:}

RH \& QQY: Study design, data collection and analysis.

RH, QQY, GHZ, BQL \& SZH: Manuscript preparation, drafting and revising.

RH \& GYL: Review and final approval of manuscript, are responsible for integrity of research. 